\title{
Science communication scholarship in Lithuania: A scoping study
}

\author{
Auste Valinciute, Vilnius University, Faculty of Communication \\ auste.valinciute@kf.stud.vu.It
}

\begin{abstract}
This study analyzes the extent, range and nature of science communication scholarship in Lithuania. The purpose of this study is to explore whether there is a presence of this research field in the Lithuanian academic context and if there exists a body of empirical evidence that can be used to inform practical science communication initiatives. More generally, this study asks: is there a science of science communication in Lithuania? Results indicate the presence of an emerging field of research with fragmented scientific activity. Most papers do not explicitly identify "science communication" as the object of study. Most of the relevant work is focused on audience research, indicating the potential for using the results for evidence-based science communication practice. The science of science communication in Lithuanian, however, has yet considerable room for growth and could benefit from more large-scale, nationally representative, data-driven and methodologically sound research.
\end{abstract}

\section{Keywords}

science communication, scoping study, content analysis, Lithuania

\section{Introduction}

The anti-vaccination movement, climate change denial and the perceived risk of GMOs are just some of the issues illustrating the paradox imbuing science and society: despite robust scientific knowledge in these areas, some members of the population hold attitudes and make decisions that are inconsistent with scientific evidence (Kahan, 2015; PEW, 2015). This paradox evokes a series of questions, such as: how do scientific controversies emerge, how do individuals form opinions and make science-related judgements and what course of action is the most effective for reducing public disagreements over science, which oftentimes can jeopardize not only scientific advancement, but can also be detrimental to the quality of our environment, well-being and health? The science of science communication is an area of research that analyzes such questions using modern empirical social science methods (Fischhoff \& Scheufele, 2013; Kahan, 2015).

Science communication, however, is both - a field of academic inquiry and pro- fessional practice (Priest, 2010). As a real-world process, science communication is defined by the U.S. National Academies of Science, Engineering and Medicine (NASEM) as the "exchange of information and viewpoints about science," the goals of which may range from understanding the nature of public concerns and increasing people's knowledge of specific science-related issues to influencing their opinions, behavior and policy choices (NASEM, 2017).

It is believed that effective science communication can play a critical role in reducing science-related controversies in the public sphere and facilitating a mutually beneficial relationship between science and society, however, science communication must be evidence-based. With the accelerating speed of scientific and technological advancement and its increasing role in our everyday lives, a field analyzing how people think about science, why they think about science the way they do and what methods can ensure a bi-directional understanding between science and society is as relevant as ever. This article investigates the science of sci- 
ence communication in Lithuania and for this purpose, employs a scoping study to explore its extent, range and nature.

\subsection{Why is it important to analyze academic fields and research agendas and why do local contexts matter?}

Prior to explaining the rationale for this study, it may be useful to elaborate on the general importance of the science of science communication. Here, three broad arguments can be made. First, empirical research works to test intuitive beliefs about the problem causes and effects of phenomena. Although the institutionalization of science communication can still be considered as relatively recent (Trench \& Bucchi, 2010; Trench \& Bucchi, 2014), the area has been suffused by its share of false premises and myths. Among the most persistent of these is the commonly held assumption that social conflicts over science arise simply because people do not understand or do not know enough about the debated scientific issues (Nisbet \& Scheufele, 2009). This assumption is followed by a belief that science-related controversies can be reduced by increasing the amounts of factual scientific information in the public sphere, which will fill people's gaps in knowledge and work to align public attitudes to the scientific consensus (Bodmer, 1985; Simis, 2016). This epitomizes what science communication scholars call the knowledge deficit model (Brossard \& Lewenstein, 2010) or what Kahan (2015) refers to as the "public irrationality thesis," which has served as the archetypical account for explaining public reactions to science and for decades has influenced practical science communication efforts (NASEM, 2017).

Research emerging from the science of science communication, however, has revealed that deficit model assumptions may be too simplistic or at the very least not generalizable. Analysis of large-scale surveys, for example, has shown that in some cases the effects of knowledge on public attitudes are essentially marginal (Allum et al., 2008) with factors such as personal characteristics, values, and me- dia having a more profound influence in shaping what some people think about science (Brossard et al., 2005; Ho et al., 2008; Scheufele \& Lewenstein, 2005). Furthermore, contrary to intuitive belief, some people with higher levels of scientific knowledge and numeracy skills are sometimes even less concerned about certain aspects of scientific issues in comparison to those whose literacy measures are lower (Kahan, 2012). The science of science communication, therefore, has not only uncovered a lack of strong empirical support for seemingly plausible hypotheses explaining public reactions to science, but has also suggested that the top-down, oneway, factual information-driven approach to science communication synonymous with the deficit model may be ineffective in reducing science-related controversies.

This leads to the second argument for the importance of the science of science communication. Ineffective science communication will result in a waste of time, funds and missed opportunities. The nonsubsiding conflicts over existing science issues and those likely to emerge from new areas such as genome editing, for example, the increasing politicization of science and its polarizing effects and the growing threats posed by scientifically uninformed policy decisions and choices - all suggest that when it comes to science communication, spontaneous or unproved methods may not constitute the best course of action. Basing practical science communication efforts on data and empirically tested strategies can help to avoid numerous setbacks (Nisbet \& Scheufele, 2009; Fischhoff \& Scheufele, 2013; Kahan, 2015; NASEM, 2017). For years, however, practical science communication efforts have been largely out of tune with evidence emerging from the social sciences. Researchers, for example, suggest that one useful strategy for communicating about science involves framing issues in a way that resonates with people's underlying beliefs and values (Scheufele, 2006; Dahlstrom, 2014; Maibach et al., 2010; Anderson et al., 2013). This approach can make science related issues more understandable and personally relevant, simultaneously evoking con- 
siderations that may not be tapped by factual information alone (Nisbet \& Mooney, 2007). At the same time, public reactions to specific science issues and interpretation of science information will likely differ across cultures pointing to the importance of country-specific and cross-cultural science communication research agendas and the overall need for developing science communication as an academic field at national levels (NASEM, 2017; Gaskell et al., 2000).

The present study is used to analyze science communication research in Lithuania in terms of its extent, range and nature. The purpose of this study is to explore whether there is a presence of this field in the Lithuanian academic context and if there exists a body of empirical evidence that can be used to guide science communication practice. In other words, this study asks - is there a science of science communication in Lithuania? Research questions are as follows:

RQ1: How has the volume of research focused on science communication and the broader area of science and society changed over time in Lithuania? RQ2: What areas of the field and what issues are being analyzed?

RQ3: What research methods are being used to analyze the field in Lithuania?

RQ4: What is the potential for the international reach of Lithuanian research on science communication?

RQ4.1: What is the most prominent demographic focus of research?

RQ4.2: How many articles are being published in English?

By gathering and synthesizing relevant literature, scoping ${ }^{1}$ offers better "conceptual clarity” (Davis, Drey \& Gould, 2009) about the state-of the art in a specific field or topic and was, therefore, chosen as the most useful approach for implementing this

1 Sometimes also referred to as mapping studies. Distinction between the two is ambiguous. While some authors differentiate between scoping studies and mapping studies (see Perryman, 2016), others use the terms interchangeably (see Dijkers, 2015). study (Arksey \& O'Malley, 2005; Ehrich et al., 2002; Anderson et al., 2008).

\subsection{The broader relevance of the Lithuanian example}

Although this paper reports on a single country analysis, the relevance of the Lithuanian case can go beyond its local focus. First, taken together such country-specific profiles can depict the global dispersion of a field, help to identify the most active regional research clusters, international frontrunners and country-areas of expertise. According to Trench and Bucchi (2014) "the proliferation of science communication activities and institutions across the globe" along with the "differences and similarities between countries and regions in the organization of these activities" has become a special interest in science communication research.

Secondly, such studies can also help to understand how fields emerge and develop. Even though over the last decades science communication has spread globally, not all countries are moving at a similar pace (Trench \& Bucchi, 2014). In 2012, for example, the European Commission released a monitoring report (MASIS), evaluating the implementation of "Science and Society" programs across twenty-seven EU and eleven associated countries. According to the assessed parameters, Lithuania along with six other countries, including Albania, the Czech Republic and Israel, was identified as having a "fragile" science communication culture. Poor national science communication infrastructure and lack of actors involved in science communication activities were accentuated as several points of concern (Mejlgaard et al., 2012).

Institutionalization levels, political support and academic traditions related to science communication are regarded as some of the general indicators of science communication culture and the drivers for field development (Mejlgaard, 2012; Trench et al., 2014). Indeed, it can be argued that in countries like the United States and the United Kingdom, impetus for the development of science communication as an academic discipline was sig- 
nificantly influenced by institutional values, legislative incentives and the overall importance that universities traditionally placed on public engagement.

Public engagement in the United States has been one of the core missions of land-grant universities since the beginning of the 20th century. Historically, schools such as Cornell, the Massachusetts Institute of Technology and the University of Wisconsin-Madison to name a few, were established in response to the growing need of agricultural and technical expertise and the aim of providing the working classes with practical higher education. However, given their applied orientation, two Congressional acts, namely the Hatch Act of 1887 and the Smith-Lever Act of 1914, impelled land-grant schools to foster closer cooperation between researchers and the lay public and ensure the transfer of scientific knowledge to its end-users beyond the university campus (APLU, 2012). Creation of what are known as extension programs served as one of the means for bridging the boundary between universities and their respective communities and bringing the benefits of research beyond the confines of the scientific laboratory. Public engagement, therefore, was engrained into the fabric of the university culture, which concurrently accelerated the need for a new area of expertise, dealing with the communication of complex information to non-specialist audiences. Not coincidentally perhaps, it was at the University of Wisconsin-Madison, a prominent land-grant university in the American Midwest, that the first department in the world for agricultural journalism was established in 1908 (Powers, 1983).

The institutional support and advancement of public engagement through Congressional legislation, therefore, highlighted its importance, accelerated practical efforts and interest in academic research and in that sense, at least to some extent, was consequential for the formation of this academic field. The same may be said for the United Kingdom, where a 1985 report by the Royal Society, discussing public understanding of science, had a number of wide-reaching outcomes, among which were the establishment of an institutional infrastructure for science communication in the UK, and an overall transformation of the perceptions about science communication and its importance for the academic community and society in general (Miller, 2001).

The development of public engagement (or science communication) in Lithuania is taking a different, but likely not a unique trajectory. In Lithuania, the institutional infrastructure and political support for science communication is relatively weak. National funding to support practical science communication is scarce and research in this specific area is not initiated by any types of grants. One of the main science events in the country - a yearly nationwide science festival - is financed by the European Social Fund for the 20142020 period. Although science communication research projects could be financed through general national research funding schemes or EU Structural Funds, to the author's knowledge, Lithuanian researchers have not yet made active use of this opportunity. While the Lithuanian Academy of Science declares "science popularization" as part of its organizational mission, without a clear science popularization strategy, action plan or benchmarks, the efforts can overall be best described as random and their impact remains unclear.

Despite frail public engagement traditions and institutionalization, however, new developments are beginning to emerge. Even though none of the 40 national universities, research institutes or colleges in the country offer degrees in science communication, in 2016 Vilnius University Faculty of Communication began to offer a so-called specialization track in science communication as part of its Cultural Communication undergraduate program. Given the low number of students that have selected this track, however, the future of this specialization is unknown. All in all, it is interesting to observe what will be the impetus for the development of science communication/public engagement tradition in Lithuania - will it develop from institutional incentives or will, perhaps academic research catalyze its growth? 
Finally, the Lithuanian case will bring in a new angle to a field that is otherwise largely dominated by Western perspectives, with most of the research emanating from United States and the United Kingdom. For example, a 2012 mapping project by Borchelt showed that researchers from North America and the UK authored more than $60 \%$ of science communication articles written from 2000 to 2009. Bauer and Howard's (2012) analysis of papers published in the journal "Public Understanding of Science" revealed that two-thirds of the articles written between 1992 and 2010 originated from US, UK, Canada, Australia and New Zealand. Guenther and Joubert's (2017) analysis of three prominent science communication journals confirms this trend by finding that most papers (almost 55\%) published between 1979-2016 came from US and UK institutions. Schäfer's (2012) meta-analysis of studies examining media coverage of science found that Western countries also dominate as the focus of research itself, so much so that at no point between 1956 to 2009, did there appear more than $1.6 \%$ of studies that analyzed media coverage of science in non-Western countries. According to the author, studies examining media coverage of science in Eastern European, South American or Asian countries "are extremely rare."

On the one hand, such findings should neither surprise nor be immediately read as indications of some systemic biases in the culture of scientific publishing United States and the United Kingdom are pioneering countries in science communication, both as a field of research and practice, which could explain the high rates of publishing in this area. On the other hand, such findings raise several interesting questions - for example, is it really the case that science communication is a predominantly Western area of research or are there perhaps other barriers, such as the tendency to publish in one's native language, that render a large body of research from other countries as off-themap? In other words, to what extent are these findings truly reflective of the global science communication research land- scape? Country-specific analyses, such as this, may contribute to this answer.

\section{Method}

Scoping is a structured approach to the gathering and synthesis of scholarly literature (Colquhoun, 2016; Davis et al., 2009; Perryman, 2016). Scoping studies are used to aggregate existing research on a specific topic, field or other domain of interest and build a map in terms of its range and other predetermined variables (Ehrich et al., 2002; Arksey \& O'Malley, 2005). This may be driven by the need to assess the volume (scope) of research literature (Grant \& Booth, 2009), evaluate the potential for a systematic review (Colquhoun, 2016) or implement other research goals that the investigator specifies through clearly defined research questions. In general, however, scoping studies are considered to be a rapid, systematic approach for identifying the "current state of understanding" and revealing gaps in knowledge, if such exist (Anderson et al., 2005).

The systematic nature of scoping studies stems from the rigorous and transparent research protocol that the studies follow (Arksey \& O'Malley, 2005). Scoping studies are quantitative in nature and do not offer any type of an interpretation of the gathered literature or an assessment of its quality (Levac, 2010; Perryman, 2016). Because selected scholarly literature is categorized and analyzed according to predefined variables, in that sense scoping studies may share similarities with content analyses.

\subsection{Operationalizing "science communication research"}

As an academic field, science communication deals with a variety of processes at the intersection of science and society. The complexity and breadth of these processes is reflected in the particularly broad and highly interdisciplinary research agendas of science communication scholars, at the same time making it difficult to delineate and pre-define the topical boundaries of this field. Two problems further compli- 
cate the task, namely, the variance in the terminology used to refer to this field or the processes that it analyzes (e.g. public communication of science, public engagement with science) and the fuzzy boundaries between science communication and other related fields of study, such as health communication or science and technology studies, for example. Although Bucchi and Trench (2016) argue that over the past decades science communication has "stabilized as the preferred descriptor" of the field, its conceptual boundaries are nevertheless ambiguous.

A series of steps were taken to operationalize the concept of "science communication research" for this study. First, the aims and scope descriptions of three prominent international outlets for science communication research ("Science Communication," "Public Understanding of Science" and "The Journal of Science Communication") were explored to understand what falls within the realm of science communication studies. The analysis showed that science communication research is not confined solely to the communication, i.e. transmission of science-related information and represents a much wider area of interests, issues and concepts that are applied to study science in its broader societal context. Therefore, to ensure that the full spectrum of studies would be captured during the sampling process, in this paper "science communication research" was too understood rather broadly and was taken to mean any type of research that focuses on the social dimensions of science in the past or present and/or research that can be considered relevant to its understanding. This may include: research that focuses on any aspect related to scientific information or its communication in the public sphere with non-expert audiences (for example, science journalism, media coverage of science, science communication methods and tools, science-related messaging studies, etc.); any kind of research measuring public reactions to science-related topics or issues (for example, awareness, understanding, perceptions, opinions, beliefs, decision-making and behavior, etc.); re- search measuring scientists' participation and views on public engagement (for example, frequency of engagement, motivation and barriers to public engagement); research analyzing science audience characteristics (for example, demographic and personal predispositions of science audiences in relation to science related issues, such as knowledge levels, deference to scientific authority and political ideology); research on the economic, legal, cultural, moral, ethical or otherwise philosophical aspects of science in society. Needless to say, what constitutes science communication research is a difficult task. Besides the aforementioned guidelines, it was decided that another helpful method for operationalizing "science communication research" is not by defining what it is, but rather what it is not. For this reason, extensive exclusion criteria were developed and applied during the sampling of publications to aid the data collection process.

\subsection{Data collection}

The sampling for this scoping study was done in two stages. The first stage involved a search in the Lithuanian Electronic Academic Library database (https://www. elaba.lt/elaba-portal/en) using a list of keywords (see table 1) related to public communication of science in addition to a set of keywords related to seven specific, arbitrarily chosen science-related issues or fields that commonly appear (or used to appear) in science communication research studies. A decision to include the latter keywords in the search was made with the intention of expanding the sample size for the study by capturing publications that while may not explicitly mention science communication, would nevertheless fall within the scope of science communication or science and society studies. The chosen database is the largest consolidated database for access to Lithuanian scholarly literature. This database integrates all open access and subscription-based databases from more than 20 Lithuanian higher education institutions and covers all types of international and non-international Lithuanian research publications, from academic arti- 
Table 1: Search strategy and results

\begin{tabular}{|c|c|c|c|c|}
\hline Keyword & Full Lithuanian keyword & Truncated keyword & Total & $\begin{array}{r}\text { After first level } \\
\text { screening }\end{array}$ \\
\hline Science communication & $\begin{array}{l}\text { Mokslo komunikacija } \\
\text { Mokslo sklaida }\end{array}$ & $\begin{array}{l}\text { moks }{ }^{*} \text { kom }^{*} \\
\left(\text { moksl }^{*} \text { sklaid*) }\right.\end{array}$ & $\begin{array}{l}4773 \\
1663\end{array}$ & $\begin{array}{l}33 \\
19\end{array}$ \\
\hline Science and society & Mokslas ir visuomenè & mokslas visuomen* & 1660 & 33 \\
\hline Popularization of science & Mokslo populiarinimas & moksl ${ }^{*}$ populiarinim* & 644 & 10 \\
\hline Popular science & Populiarus mokslas & (populiar* moksi*) & 2128 & 51 \\
\hline Science and the media & Mokslas ir žiniasklaida & moksl $^{*}$ ziniasklaid ${ }^{*}$ & 756 & 24 \\
\hline Literacy & Raštingumas & rastingum* & 558 & 15 \\
\hline Risk communication & Rizikos komunikacija & rizik* komunikacij* $^{*}$ & 75 & 8 \\
\hline Health communication & Sveikatos komunikacija & sveikat* komunikac* & 215 & 7 \\
\hline Genetically modified (GMO) & $\begin{array}{l}\text { Genetiškai modifikuoti } \\
\text { GMO }\end{array}$ & $\begin{array}{l}\text { genet* modifikuot* } \\
\text { GM0 }\end{array}$ & $\begin{array}{c}62 \\
138\end{array}$ & $\begin{array}{l}11 \\
13\end{array}$ \\
\hline Cloning & Klonavimas & klon* & 361 & 8 \\
\hline Climate change & Klimato kaita & klimat* kait* & 580 & 11 \\
\hline Global warming & $\begin{array}{l}\text { Visuotinis atšilimas } \\
\text { Globalus atšilimas }\end{array}$ & $\begin{array}{l}\text { visuotin* atsilim** } \\
\text { global* }^{*} \text { atsilim** }\end{array}$ & $\begin{array}{l}11 \\
59\end{array}$ & $\begin{array}{l}0 \\
0\end{array}$ \\
\hline Vaccine/Vaccination & $\begin{array}{l}\text { Skiepai/Skiepijimas } \\
\text { Vakcinos/Vakcinacija }\end{array}$ & $\begin{array}{l}\text { skiep* }^{*} \\
\text { vakcin* }\end{array}$ & $\begin{array}{l}301 \\
292\end{array}$ & $\begin{array}{r}13 \\
7\end{array}$ \\
\hline Embryonic stem cells & Embrioninės kamieninès ląstelès & embrion* & 247 & 14 \\
\hline Shale gas & Skalūnų dujos & skalūn* duj* & 12 & 1 \\
\hline \multirow[t]{2}{*}{ Nuclear energy } & Branduolinė energetika & branduolin* energetik* & 419 & 10 \\
\hline & & & Total & 288 \\
\hline
\end{tabular}

cles and books to conference proceedings and dissertations.

This database was picked instead of other databases that are frequently used in systematic reviews or meta-analyses (e.g. Web of Science or Scopus) due to the specificity of the scientific publishing culture in Lithuania. A 2015 Lithuanian research assessment conducted by the Research and Higher Education Monitoring and Analysis Center (MOSTA) in consultation with the Research Council of Lithuania showed that the international reach of social science and humanities research is limited. Projects are most often written in Lithuanian, there is a disproportionate focus on local issues and articles are usually published in national university-owned academic journals (MOSTA, 2015). While most of these journals are peer reviewed, the majority are not indexed by platforms such as Web of Science or Scopus. Data collection using the latter platforms, therefore, would simply not capture the material relevant for this study.

Due to the complexities of the Lithuanian language, for example, the large variety of suffixes and word endings, each keyword was truncated, to ensure that all possible forms of the terms and phrases were included in the search. For the purpose of this study, only academic research papers were included with no restrictions on the year of publication. Initial screening (first level screening) of results from the database search involved reading the title and abstract of the articles to determine their eligibility for this study. The following exclusion criteria was applied: articles without an abstract; inaccessible articles (broken links); non-academic articles; conference proceedings; book reviews; biographies; articles in languages other than Lithuanian or English; articles that did not have a clear science and society focus including articles that focused on the topics of: formal science communication (communication between scientists), open access publishing, digitalization, science metrics, public communication of social sciences, humanities or arts and/ or their related topics, higher education management, higher education marketing, knowledge management, IT, language literacy, science-business relationship). 
Because first level screening involved reading only the title and abstract of the articles, to avoid a mistaken elimination of an article, application of the exclusion criteria at this point was somewhat liberal - if the title and abstract were in any sense ambiguous and/or if the researcher was unsure whether the article was eligible for this study, the article was marked as eligible. After first level screening, a total of 288 articles were selected for further analysis. Here, 105 of the 288 articles were deleted as duplicates due to their reoccurrence in-between different keyword search results. This left a total of 183 articles for in-depth analysis (second level screening), which involved reading the title, abstract, introduction and the conclusion sections of articles, after which a further 80 articles were eliminated, because they did not meet the inclusion/exclusion criteria. In sum, the first stage of sampling captured 103 articles for coding.

The second stage of sampling involved what is known as the snowballing technique, where article reference lists are checked to identify additional relevant literature (Wohlin, 2014). The snowballing technique was applied twice - first, it was applied to the articles found through the database search (103 articles) which gave an additional 59 articles for further analysis. Snowballing was then applied to the latter group of articles, finding 26 more articles to be analyzed. The application of the snowballing technique added a total of 85 articles to the pre-sample of which 49 were deleted because they did not meet the inclusion/exclusion criteria. The final sample, therefore, consisted of 139 articles that were selected for coding: 103 articles from the database search and 36 articles found through snowballing.

During the course of this study, a decision was made not to include articles that focused on science education, unless the primary object of research concerned teachers' or students' scientific literacy, which represents a prominent issue in science communication research. This decision was motivated by a few factors. Lithuanian scholars are noticeably active in science education research. A search with the keyword "gamt* udgym*" (science education) found 629 articles of which 191 were focused on science education (the rest were false positives). However, because science education has a number of research journals in Lithuania, it was determined that it would be impossible to reflect the full body of research being carried out in this area without analyzing the entirety of content found in these specific journals, which was beyond the reasonable volume of investigation for this study.

\subsection{Coding}

After completing the sampling process, the publications were coded using a scheme developed to answer the research questions of this study (see table 2). Some of the categories and variables of this coding scheme were based on a similar study by Xu et al. (2015) analyzing science communication scholarship in China, but were in most cases adjusted to fit the purpose and analytical goals of this paper.

The coding scheme consisted of seven categories: year, area of analysis, main issue of analysis, methodological approach, research method, demographic focus and language. The category "Year" was defined as the year in which the article was published. Category "Area of analysis" was defined as the broad subject of the publication. Category "Main issue of analysis" was defined as the topic, e.g. the particular aspect of the subject that was being analyzed in the publication. Category "Methodological approach" was defined as the type of investigation that was being reported on in the article and the category "Research method" - the specific procedure used to collect data. Category "Demographic focus" was defined as the geographical boundaries of populations or problems being analyzed. Category "Language" was defined as the language in which the article was written.

Except for the year of publication, each category had a set of predetermined variables (see table 2) for the articles to be assigned to. Variables for categories "Methodological approach" and "Research method" were derived from general literature on research methodology (e.g. Bry- 
Table 2: Coding scheme

\begin{tabular}{|c|c|c|}
\hline Category & \multicolumn{2}{|l|}{ Variables } \\
\hline Year & \multicolumn{2}{|c|}{ (no predetermined) } \\
\hline \multirow[t]{5}{*}{ Area of analysis and main issue } & Society & $\begin{array}{l}\text { Legal issues; Policy; Politics; Culture; Ethics/moral issues; } \\
\text { Economy/economic issues; Organizations; Processes; Projects; } \\
\text { Religion }\end{array}$ \\
\hline & Content & Media representation; Discourse; Documents; Language; Strategies \\
\hline & Audience & $\begin{array}{l}\text { Attitude; Opinion; Behavior; Awareness; Understanding/Knowledge; } \\
\text { Communication methods }\end{array}$ \\
\hline & Theory & Concepts; Philosophy; Methodology; Models; Field \\
\hline & Historical & \\
\hline Methodological approach & \multicolumn{2}{|c|}{ Quantitative; Qualitative; Mixed; None } \\
\hline Research method & \multicolumn{2}{|c|}{$\begin{array}{l}\text { Literature analysis; Comparative analysis; Secondary analysis; Content analysis; } \\
\text { (Critical) discourse analysis; Survey; Interview; Experiment; Case study/Observation; } \\
\text { Report; Essays with no specific method application }\end{array}$} \\
\hline Demographic focus & \multicolumn{2}{|c|}{ None; Local; International; Mixed } \\
\hline Language & \multicolumn{2}{|c|}{ Lithuanian; English } \\
\hline
\end{tabular}

man, 2012). Variables for categories "Demographic focus" and "Language" were likewise considered to be less ambiguous. In regard to demographic focus, it was decided that the publication could either be centered on local, international or local and international (e.g. mixed) problems or populations. The fourth variable for this category, i.e. "general (none)" was included to account for publications that had no specific demographic focus in that they analyzed broadly applicable, noncontextualized topics. So, for example, an article on public perceptions of ecological and technological risk in Lithuania would be coded as having a "local" demographic focus, whereas an article about the scientific-moral problems of stem-cell research would be understood as having no specific geographic boundaries and would, therefore, be coded as "general (none)."

Variables for categories "Area of analysis" and "Main issue of analysis" were generated using an iterative approach. For the initial selection of variables for these categories a reference was made to a coding scheme from a similar study by $\mathrm{Xu}$ et al. (2015) analyzing science communication scholarship in China. After creating a coding scheme blueprint, the process was followed by a discussion with two fellow scholars, the purpose of which was to generate additional mutually exclusive variables for making an exhaustive list of choices for the aforementioned categories.

After testing the coding scheme on an arbitrary selection of articles from the sample, additional variables were found for the category "Main issue of analysis" and were added to the variable list. Regardless of what was believed to be a sufficiently robust coding scheme, understanding the breadth of possible research areas and issues of analysis, it was decided to permit ad-hoc additions of variables, if that was deemed to be necessary during the data analysis process ${ }^{2}$. As an example of coding for these categories, an article analyzing the concept of mathematical literacy would be coded as the following: "Area of analysis = theory" and "Main issue of analysis=concept," whereas an article analyzing philosophical ideas on the role of science in postmodern societies would be coded as "Area of analysis = theory" and "Main issue of analysis = philosophy." An article analyzing the dissemination of science information in $18^{\text {th }}$ century calendars

2 During the coding process one such addition was made to the category "Main issue of analysis," after coming across two articles that were specifically and unambiguously focused on the analysis of "projects" - a variable that was unforeseen in the coding scheme. 
would be coded as "historical research". An article measuring university students' literacy on biotechnology would be coded as "Area of analysis = audience" and "Main issue of analysis = knowledge." An article analyzing the use of metaphors in popular science magazines would be coded as "Area of analysis = content," "Main issue of analysis = language" and so forth .

\section{Results}

\subsection{Extent and range of publications}

Except for one publication in 1997, articles relevant to science communication start appearing at the beginning of 2000 and gradually increase until 2008, when the number of publications reaches a peak with fifteen articles published in a single year (see figure 1).

Over the course of the decade between 2000 and 2010 when a total of 88 articles were published, the majority focused on audience and theoretical research $(31 \%$ and $30 \%$ respectively) (figure 2). Among the popular issues and topics of interest were risk perception, public opinion and scientific literacy. Many articles focused on biotechnology, particularly genetically modified food, correlating with the global emergence of genetic engineering during the period. Since 2010 the number of studies related to science communication seems to be accelerating, with a total of 50 articles already published between 2011 and 2015. However, although there has been a considerable increase in the overall volume of publications since the end of the 1990s, Lithuanian science communication scholarship does not show a stable upward trend, observed in similar studies that tracked the volume of science communication research in other countries (Xu et al., 2015), specific journals (Guenther \& Joubert, 2017) or the general context (Borchelt, 2012).

Overall, much of research between 1997 and 2015 is focused on various fac-

3 A decision was made not to code "historical research" into further variables, due to the difficulty of identifying specific research questions leading the publications. ets of audience analysis (37\%), theoretical $(23 \%)$ and society-related issues $(22 \%)$ (figure 2). Although a direct comparison of results is difficult due to differing study methodologies, a focus on audience research is also apparent in other similar analyses of science communication research conducted thus far (see, for example, Bauer \& Howard's [2012] analysis of publishing in one of the prominent journals in the field). In contrast to trends observed in the international science communication context (Weitkamp, 2016; Bauer \& Howard, 2012; Schäfer, 2012), content-related studies in Lithuania seem far less popular compared to other areas of research, making up $14 \%$ of the total sample. The least number of articles (4\%) was found in the area of historical research.

A similar distribution is also apparent when measuring not only the primary but also the secondary area of research in the sample. The secondary area of research is understood either as a second research question or a subtopic within the study. Of the 53 articles that were determined to have a secondary area of research, $51 \%$ focused on audience analysis, $17 \%$ focused on theoretical inquiries and $11 \%$ on society related issues.

Table 3 presents findings on what specific topics or aspects of science communication or the science and society relationship more broadly, are being analyzed within the identified research areas of the sampled publications. Because a relatively large number of articles focused on more than one area or issue of analysis, it was decided to record a primary and a secondary area and/or issue of analysis where needed, to reflect this diversity.

Overall ${ }^{4}$, within the area of "Society" related studies, ethics, morality, politics and legal issues were found to be the most prevalent topics of analysis. "Content" focused studies mostly examined media

4 The following numbers were generated by adding up the occurrences of each issue both as primary and secondary issues of analysis. That is why the total number of articles in the Issues column (table 3) may exceed the total number of articles $(\mathrm{N})$ in that particular area. 
Figure 1: Volume of publications over time

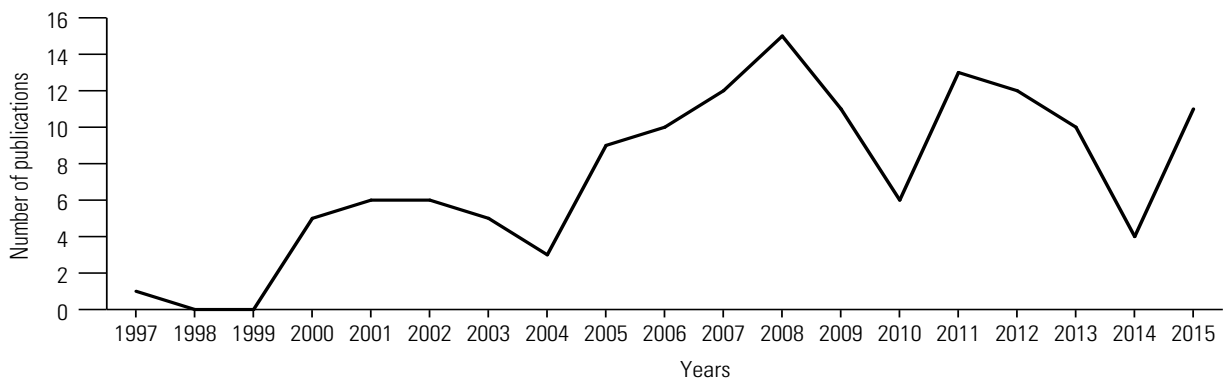

Figure 2: Main and secondary areas of research

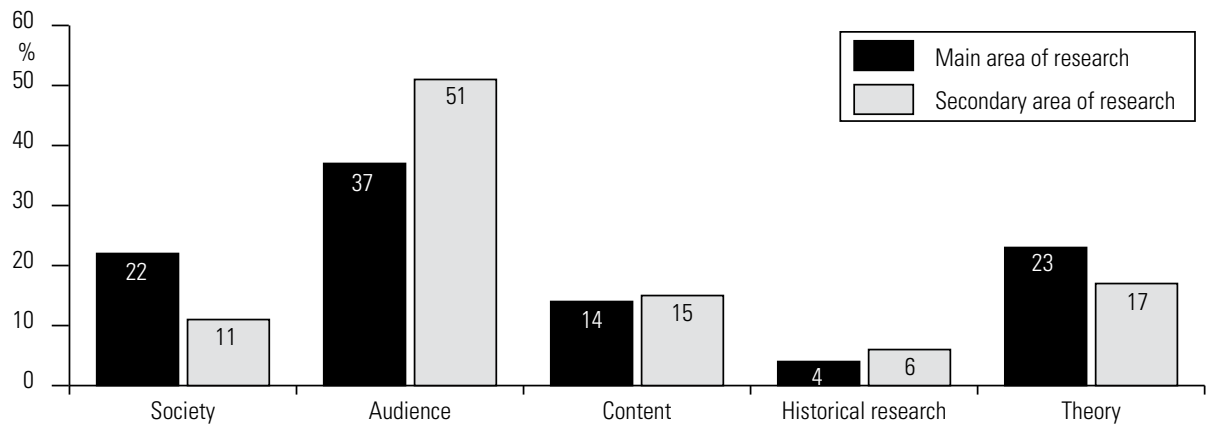

representation of various science related issues and/or processes and the usage of language in science communication. "Audience" research studies were primarily focused on measuring public attitudes, opinions and knowledge/understanding of science related issues. Theoretical research studies mainly presented examinations of various concepts and philosophical discussions related to the science and society relationship and its meaning.

\subsection{Nature of publications}

Forty percent $(40 \%)$ of analyzed publications used a qualitative methodological approach and $31 \%$ of publications were quantitative in nature (see table 4). A fifth (20\%) of the total publications used a mixed methods design, combining quantitative and qualitative methods for answering research questions.

The most prevalent research method in qualitative studies was literature analysis, followed by qualitative content analysis, discourse/critical discourse analysis and very occasional use of observation/ case studies. Surveying is by far the most popular research method used in quantitative studies, which appears to be a general trend in science communication research methodology (Bauer \& Howard, 2012; Borchelt, 2012). Of the sampled publications, only two studies out of 139 were experimental in nature. In studies with a mixed methods approach, the most frequently used research methods were: quantitative and qualitative content analysis, quantitative and qualitative survey and literature analysis ${ }^{5}$. There was a total of 11 publications $(9 \%)$ that did not employ any type of research method. In this paper, such publications were coded as essays.

Regarding the demographic focus of publications, an immediately striking

5 The total number of research methods used may exceed the total number of publications. This discrepancy appears because some authors used more than one method in their research. 
Table 3: Main issues of analysis

\begin{tabular}{|c|c|c|c|}
\hline Area of analysis & $\begin{array}{l}\text { Issue of analysis } \\
\text { As a main issue: }\end{array}$ & $\begin{array}{l}\text { Issue of analysis } \\
\text { As a secondary issue: }\end{array}$ & Total occurrences \\
\hline \multirow[t]{10}{*}{ Society ( $N=31$ ) } & Legal issues $(n=6)$ & Legal issues $(n=0)$ & 6 \\
\hline & Policy $(n=1)$ & Policy $(n=0)$ & 1 \\
\hline & Politics $(n=4)$ & Politics (n=3) & 7 \\
\hline & Culture $(n=3)$ & Culture $(n=0)$ & 3 \\
\hline & Ethics/moral issues $(n=8)$ & Ethics/moral issues $(n=0)$ & 8 \\
\hline & Economy/economic issues $(n=3)$ & Economy/economic issues $(n=0)$ & 3 \\
\hline & Organizations $(n=2)$ & Organizations $(n=1)$ & 3 \\
\hline & Processes $(n=2)$ & Processes $(n=0)$ & 2 \\
\hline & Projects $(n=2)$ & Projects $(n=0)$ & 2 \\
\hline & Religion $(n=0)$ & Religion $(\mathrm{n}=2)$ & 2 \\
\hline \multirow[t]{4}{*}{ Content $(\mathrm{N}=20)$} & Media representation $(n=11)$ & Media representation $(n=4)$ & 15 \\
\hline & Discourse $(n=2)$ & Discourse $(n=3)$ & 5 \\
\hline & Language $(n=7)$ & Language $(n=0)$ & 7 \\
\hline & Strategies $(n=0)$ & Strategies $(n=1)$ & 1 \\
\hline \multirow[t]{6}{*}{ Audience $(\mathrm{N}=51)$} & Attitude $(n=12)$ & Attitude $(\mathrm{n}=7)$ & 19 \\
\hline & Opinion $(n=12)$ & Opinion ( $n=12$ ) & 24 \\
\hline & Behavior $(n=10)$ & Behavior $(\mathrm{n}=3)$ & 13 \\
\hline & Awareness $(n=4)$ & Awareness $(\mathrm{n}=2)$ & 6 \\
\hline & Understanding/knowledge $(n=12)$ & Understanding/knowledge $(\mathrm{n}=3)$ & 15 \\
\hline & Communication methods $(n=1)$ & Communication methods $(n=0)$ & 1 \\
\hline \multirow[t]{4}{*}{ Theory $(\mathrm{N}=32)$} & Concepts ( $n=13$ ) & Concepts $(n=4)$ & 17 \\
\hline & Philosophy $(n=10)$ & Philosophy (n=2) & 12 \\
\hline & Methodology $(n=6)$ & Methodology $(\mathrm{n}=2)$ & 8 \\
\hline & Field $(n=3)$ & Field $(n=1)$ & 4 \\
\hline Historical research $(\mathrm{N}=5)$ & & & 5 \\
\hline
\end{tabular}

finding of this study is that publications with an international focus made up just a small fraction (4\%; six articles out of 139) of the total sample (table 5) with $72 \%$ of analyzed articles focused on the Lithuanian context, analyzing audiences, issues, concepts, events and other aspects of the science and society relationship in the local setting (see table 5). Roughly a fifth $(22 \%)$ of the total number of publications were focused on generally applicable, non-contextualized topics. In their analysis of science communication scholarship in China, Xu et al. (2015), report a somewhat similar finding, with $32.5 \%$ of research identified as not relating to a specific region.

Of the sampled publications, $80 \%$ were written in Lithuanian and $20 \%$ of the articles were written in English. Most of the publications that were written in English (a total of 29 articles) are oriented towards the local context, with three publications focused on international issues and 5 publications analyzing general, widely applicable topics, usually within the realm of methods, methodology and ethics.

\section{Summary and discussion}

This study analyzed the extent, range and nature of Lithuanian scholarship on science communication by looking at the volume of publications, most prominent areas of analysis, research methods, the demographic focus of publications and the language in which these publications were written. The purpose of this study was to build a general understanding about the state of science communication as a field of research in Lithuania and to 
Table 4: Methodological approach and most commonly used research methods

\begin{tabular}{|c|c|c|}
\hline $\begin{array}{l}\text { Methodological } \\
\text { approach }\end{array}$ & $\begin{array}{l}\text { Research methods } \\
\text { used }\end{array}$ & Number of studies \\
\hline \multirow[t]{9}{*}{ Qualitative (N=57) } & Literature analysis & 29 \\
\hline & Content analysis & 12 \\
\hline & $\mathrm{DA} / \mathrm{CDA}$ & 8 \\
\hline & $\begin{array}{l}\text { Historical research } \\
\text { methods }\end{array}$ & 6 \\
\hline & Case study & 3 \\
\hline & Interview & 3 \\
\hline & Comparative analysis & 3 \\
\hline & Reports & 1 \\
\hline & Secondary analysis & 1 \\
\hline \multirow[t]{4}{*}{ Quantitative $(\mathrm{N}=43)$} & Survey & 38 \\
\hline & Content analysis & 4 \\
\hline & Secondary analysis & 2 \\
\hline & Experiment & 2 \\
\hline \multirow[t]{6}{*}{ Mixed ( $N=28)$} & Content analysis & 18 \\
\hline & Survey & 11 \\
\hline & Literature analysis & 6 \\
\hline & Case study & 3 \\
\hline & Secondary analysis & 3 \\
\hline & $\mathrm{DA} / \mathrm{CDA}$ & 1 \\
\hline Essays (N=11) & & \\
\hline
\end{tabular}

Table 5: Demographic focus of publications

\begin{tabular}{lr}
\hline Demographic focus & Articles (\%) \\
\hline Local & 72 \\
General (none) & 22 \\
International & 4 \\
Mixed & 2 \\
\hline
\end{tabular}

explore whether there exists a body of research that can be used to guide science communication practice.

Even though most researchers do not explicitly identify "science communication" as their object of analysis, results of this study do indicate a spectrum of Lithuanian scholarly publications that can be considered as falling within the scope or being relevant to this field. On the one hand, this finding suggests that in comparison to other countries like the United States, UK or China, for example (see Xu et al., 2015), the scholarly landscape is yet too fragmented for science communica- tion to be classified as a mature, distinct field of research in Lithuania.

On the other hand, numerous aspects related to science communication or the science and society relationship more broadly, are on the agendas of Lithuanian researchers. Despite a large proportion of the studies being either literature reviews or small-scale, non-representative studies, there likely is material that could be used to begin forming a coherent, albeit a very general notion about the social dimensions of science in this local context. This in turn could serve as the building block for anchoring the field of science communication in Lithuania. It is imperative to reiterate, however, that this study did not assess the quality and methodological rigor of the analyzed articles. This is especially important, since some of the articles were published in journals that do not operate under a double-blind peer review policy. For the moment, therefore, science communication in Lithuania is still an emerging discipline. Furthermore, it is a spontaneously emerging discipline, given the lack of institutional attention given to science communication research and practice in the country.

Audience research was found to be the most prominent area of analysis among Lithuanian scholars. This is a positive finding where practical science communication is concerned. Audience research allows to understand audience characteristics, preferences, what the public finds to be important or where the majority stands on the opinion spectrum regarding various science related issues (given that the sampling is random and representative of the general population). Such analyses are not just descriptive, but also allow for science communication decisions, projects and messages to be tailored to specific audiences (Scheufele, 2006). Within the science of science communication paradigm, it is argued that it is precisely this type of an approach to practical efforts that may yield the most effective results (Nisbet, 2008).

Interestingly, despite the media serving as one of the primary sources of information for science and its role in shaping 
science related public perceptions and attitudes, Lithuanian scholars are far less active in media content research. While media content analyses are a frequent topic of science communication research in the international context (Schäfer, 2012; Weitkamp, 2016; Bauer \& Howard, 2012), such studies in Lithuania are not as common, signaling a need for more scientific contributions.

In Lithuania science communication research could also benefit from more varied methodological approaches. Experimental research is still greatly undervalued, despite its importance for evidence based practice, especially at the stage of translating plausible hypotheses into action (Kahan, 2015). One of the main arguments underlying the science of science communication is that experimental research can test what types of messages or forms of public campaigns, for example, will be effective and which will likely boomerang. This could prevent the waste of financial and human resources, and help to avoid possible backfire effects from ineffective strategies (see Nyhan et al., 2015, for example). The experimental segment of science communication research and, generally, social studies in Lithuania has yet considerable space for growth.

The same may be true for qualitative studies, where literature reviews are the most popular method of research. The prevalence of qualitative surveys/interviews or observational methods was found to be low, the samples were small and none of the studies made use of focus groups. Despite concerns regarding validity, qualitative methods can provide an in-depth understanding of social phenomena that the use of quantitative methods may sometimes make it hard to tap into. Qualitative content analyses, for example, may help to uncover the latent meaning of media texts, whereas the use of interviews and focus groups may give a better understanding of the personal motivations or reasons behind people's attitudes, opinions, beliefs and behavior related to science issues (Bryman, 2012). Nevertheless, in order to foster a scientific, evidence-based approach to science communication practice, qualitative studies should be supported by quantitative evidence, especially where large-scale projects or high-stakes decisions are concerned. All in all, reasons for the reluctance to use a greater variety of methods, especially experimental methods by Lithuanian researchers remain obscure.

This scoping study also found that researchers tend to focus primarily on the analysis of local issues, audiences and content, which comes in contrast to science communication scholarship in China, for example, where $\mathrm{Xu}$ et al. (2015) find that research is more internationally oriented. Aside from the lack of large-scale quantitative, experimental studies, this is a positive finding for anchoring science communication as a field in the national context. At the same time, however, researchers may also need to explore possible pathways for the international reach of their publications. There are several publications that could appear in meta-analyses, or overviews exploring various subjects, topics and fields (see Schäfer, 2012, for example), however this opportunity is limited by the fact that the majority of publications are not being written in English. While this is not an unexpected finding given the culture of academic publishing in Lithuania, such trends may nonetheless hinder the visibility and reach of Lithuanian scholarship in the international arena.

\section{References}

Anderson, A.A., Kim, J., Scheufele, D. A., Brossard, D., \& Xenos, M.A. (2013). What's in a name? How we define nanotech shapes public reactions. Journal of Nanoparticle Research, 15, 1421.

Anderson, S., Allen, P., Peckham, S., \& Goodwin, N. (2008). Asking the right questions: Scoping studies in the commissioning of research on the organization and delivery of health. Health Research Policy and Systems, 6(7).

Arksey H., \& O’Malley, L. (2005). Scoping studies: Towards a methodological framework. International Journal of Social Research Methodology, 8(1), 19-32. 
Association of Public and Landgrant Universities. (2012). The land grant tradition [online]. Available at: http://www.aplu.org/ library/the-land-grant-tradition/file

Bauer, M. W., Howard, S. (2012). Public understanding of science - a peer-review journal for turbulent times. Public Understanding of Science, 21(3), 258-267.

Bodmer, W. F. (1985). The public understanding of science [online]. Available at: http://royalsociety.org/uploadedFiles/ Royal_Society_Content/policy/publications/1985/10700.pdf

Brossard, D., Lewenstein, B.V. (2010). A critical appraisal of models of public understanding of science: Using practice to inform theory. In L. Kahlor \& P. Stout (Eds.), Communicating science: New agendas is science communication. New York: Routledge.

Brossard, D., Lewenstein, B., \& Bonney, R. (2005). Scientific knowledge and attitude change: The impact of a citizen science project. International Journal of Science Education, 27(9), pp. 1099-1121.

Borchelt, R. (2012). The science communication research literature mapping project. Plenary paper presented at the $12^{\text {th }}$ International Science and Technology Conference [online]. Available at: https://www. slideshare.net/OPARC1/firenze-phd-slides

Bryman, A. (2012). Social Research Methods. Oxford University Press.

Bucchi, M., \& Trench, B. (2016). Science communication and science in society: A conceptual review in ten keywords. Tecnoscienza, 7(2), 151-168.

Colquhoun, H. (2016). Current best practices for the conduct of scoping reviews [online]. Available at: http://www. equator-network.org/wp-content/uploads/2016/06/Gerstein-Library-scoping-reviews_May-12.pdf

Davis K., Drey, N., \& Gould, D. (2009). What are scoping studies? A review of the nursing literature. International Journal of Nursing Studies, 46(10), 1386-1400.

Dahlstrom, M.F. (2014). Using narratives and storytelling to communicate science with nonexpert audiences. Proceedings of the National Academy of Sciences of the United States of America, 111 (Suppl. 4), 13614-13620.
Dijkers, M. (2015). What is a scoping review? [online]. Available at: http://ktdrr.org/ products/update/v4n1/index.html

Ehrich, K., Freeman, G. K., Richards, S.C., Robinson, I.C., \& Sheppard, S. (2002). How to do a scoping exercise. Research, Policy and Planning, 20(1), 25-29.

Fischhoff, B., \& Scheufele, D. A. (2013). The science of science communication. Proceedings of the National Academy of Sciences 110 (Supplement 3), 14031-14032.

Gascoigne, T., Cheng, D. Claessens, M., Metcalfe, J., Schiele, B., \& Shi, S. (2010). Is science communication its own field? Journal of Science Communication, 09(03).

Gaskell, G., Allum, N., Bauer, M., Durant, J., Allansdottir, A., Bonfadelli, H., Boy, D., de Cheveigné, S., Fjaestad, B., Gutteling, J. M., Hampel, J., Jelsøe, E., Jesuino, J.C., Kohring, M., Kronberger, N., Midden, C., Nielsen, T. H., Przestalski, A., Rusanen, T., Sakellaris, G., Torgersen, H., Twardowski, T., \& Wagner, W. (2000). Biotechnology and the European public. Nature Biotechnology, 18(9), 935-938.

Grant, M. J., \& Booth, A. (2009). A typology of reviews: an analysis of 14 review types and associated methodologies. Health Information and Libraries Journal, 26(2), 91-108.

Guenther, L., \& Joubert, M. (2017). Science communication as a field of research: identifying trends, challenges and gaps by analysing research papers. JCOMM, 16(2), $1-19$.

Ho, S. S., Brossard, D., \& Scheufele, D. A. (2008). Effects of value predispositions, mass media use, and knowledge on public attitudes toward embryonic stem cell research. International Journal of Public Opinion Research, 20(2), 171-192.

Kahan, D. M. (2015). What is the science of science communication? Journal of Science Communication, 14(3), pp.1-12.

Kahan, D. M., Peters, E., Wittlin, M., Slovic, P., Ouellette, L. L., Braman, D., \& Mandel, G. (2012). The polarizing impact of science literacy and numeracy on perceived climate change risks. Nature Climate Change 2, 732-735.

Levac, D., Colquhoun, H., \& O'Brien, K. K. (2010). Scoping studies: Advancing the 
methodology. Implementation Science: IS, 5(69).

Maibach, E.W., Nisbet, M., Baldwin, P., Akerlof, K., \& Diao, G. (2010). Reframing climate change as a public health issue: An exploratory study of public reactions. $B M C$ Public Health, 10(1).

Mejlgaard, N., Bloch, C., Degn, L., Ravn, T., \& Nielsen, M.W. (2012). Monitoring Policy and Research Activities on Science and Society in Europe (MASIS) Final Synthesis Report. Brussels: European Commission, Directorate General for Research and Innovation.

Miller, S. (2001). Public understanding of science at the crossroads. Public Understanding of Science, 10(1), 115-120.

National Academies of Science, Engineering, and Medicine. (2017). Communicating Science Effectively: A Research Agenda. Washington, DC: The National Academies Press.

Nisbet, M.C., \& Mooney, C. (2007). Framing science. Science, 316(5821), 56.

Nisbet, M.C.,\& Scheufele, D. A. (2009). What's next for science communication? Promising directions and lingering distractions. American Journal of Botany, 96(10), 1767-1778.

Nisbet, M.C. (2008). Framing science: A new paradigm in public engagement. In $\mathrm{L}$. Kahlor \& P. Stout (Eds.), Communicating science: New agendas is science communication (pp. 40-68). New York: Routledge.

Nyhan, B., Reifler, J., Richey, S., \& Freed, G. L. (2014). Effective messages in vaccine promotion: A randomized trial. Pediatrics, 133(4), pp. 835-842.

Perryman, C. L. (2016). Mapping studies. Journal of the Medical Library Association, 104(1), 79-82.

Pew Research Center. (2015). Public and scientists' views on science and society [online]. Available at: http://www.pewinternet.org/2015/01/29/public-and-scientists-views-on-science-and-society/

Powers, R. (1983). The first 75 years: Agricultural journalism dept. University of Wisconsin-Madison [online]. Available at: http://lsc.wisc.edu/wpcontent/uploads/ sites/25/2015/07/AJHistory.pdf
Priest, S. H. (2010). Coming of age in the academy? The status of our emerging field. Journal of Science Communication(, 9(3).

Research and Higher Education Monitoring and Analysis Centre (MOSTA). (2015). Lithuania: Research Assessment Exercise Panel S1: Social Sciences [online]. Available at: http://mosta.lt/images/vertinimas/ Benchmarkingo_ataskaitos/research_assessment_exercise_social_sciences1.pdf

Schäfer, M.S. (2012). Taking stock: A meta-analysis of studies on the media's coverage of science. Public Understanding of Science, 21(6), 650-663.

Scheufele, D.A. (2006). Messages and heuristics: How audiences form attitudes about emerging technologies. In J. Turney (Ed.), Engaging science: Thoughts, deeds, analysis and action (20-25). London: The Wellcome Trust.

Simis, M. J. Madden, H., Cacciatore, M.A., \& Yeo, S. K. (2016). The lure of rationality: Why does the deficit model persist in science communication? Public Understanding of Science, 25(4), 400-414.

Trench, B., \& Bucchi, M., with et al. (2014). Global spread of science communication: Institutions and practices across continents. In M. Bucchi \& B. Trench (Eds.), The Routledge handbook of public communication of ccience and technology (2nd ed., pp. 214-230). London and New York: Routledge.

Trench, B., \& Bucchi, M. (2010). Science communication, an emerging discipline, Journal of Science Communication, 9(03).

Weitkamp, E. (2016). Five years of JCOM-inclusive, comprehensive or could we do better? Journal of Science Communication, 15(4).

Wohlin, C. (2014). Guidelines for snowballing in systematic literature studies and a replication in software engineering. In Proceedings of the 18th International Conference on Evaluation and Assessment in Software Engineering, (EASE '14).

Xu, L., Huang, B., \&Wu, G. (2015). Mapping science communication scholarship in China: Content analysis on breadth, depth and agenda of published research. Public Understanding of Science, 24(8), 897-912. 